\title{
La influencia de la asociatividad en el desarrollo de oportunidades productivas: el caso de cuatro asociaciones agropecuarias de la región Moquegua - Perú
}

Percy Bobadilla Díaz*

Martha Patricia Puente de la Vega ${ }^{* *}$

Renzo Fernández Escobar ${ }^{* *}$

- Magíster en Sociología y candidato a doctor en Sociología por la Pontificia Universidad Católica del Perú (PUCP). Actualmente, es profesor asociado de la Facultad de Ciencias Sociales, la Escuela de Posgrado, y la Escuela de Gobierno y Políticas Públicas de la PUCP. Correo electrónico: pbobadi@ pucp.edu.pe. https://orcid.org/0000-0003-1769-585X

Magister en Sociología de las Organizaciones e Instituciones de la Universidad Nacional Mayor de San Marcos y licenciada en Sociología por la Pontificia Universidad Católica del Perú. Actualmente, docente en el Departamento de Ciencias Sociales y de la Facultad de Gestión y Alta Dirección. https:// orcid.org/0000-0002-1538-5121

${ }^{* * *}$ Licenciado en Sociología por la Pontificia Universidad Católica del Perú. Actualmente, predocente en el Departamento de Ciencias Sociales, y evaluador en la Superintendencia Nacional de Educación Superior Universitaria (Sunedu). https://orcid.org/0000-0002-4707-1370

Fecha de recepción: 06/04/2020. Fecha de aceptación: 10/08/2020 


\title{
La influencia de la asociatividad en el desarrollo de oportunidades productivas: el caso de cuatro asociaciones agropecuarias de la región Moquegua - Perú
}

\section{RESUMEN}

El presente artículo se basa en los resultados del diagnóstico elaborado como parte del curso «Práctica de Campo» de la especialidad de Sociología de la Facultad de Ciencias Sociales de la PUCP en el semestre $2018-2^{1}$. Se inicia con una aproximación teórica sobre la asociatividad y la pequeña agricultura. Luego se propone una metodología mixta, recogiendo la percepción de actores del sector público, privado y académico con respecto a la importancia de este mecanismo para la inserción de cuatro asociaciones agropecuarias de la región de Moquegua en mercados nacional e internacional. A partir del análisis de la asociatividad y su relación con los capitales — humano, social, natural, físico y financiero-, se concluye que esta funciona como impulsora de oportunidades productivas, pero aún se enfrenta a desafíos para que sea una opción real en el fortalecimiento de los pequeños productores de Moquegua. En particular para las asociaciones estudiadas, el capital natural (agua o tierra) es un factor clave para la asociatividad; la tradición y cultura (capital social) fungen como lazos que fomentan la confianza en el colectivo, y las oportunidades de mercado apoyadas por agentes externos que potencian la voluntad de cooperar y asociarse. Finalmente, el marco institucional y la capacidad de gestión de estas unidades económicas serán determinantes para considerar a la asociatividad como una estrategia sostenible y de desarrollo para los pequeños productores.

Palabras clave: asociatividad, pequeńos productores, oportunidades productivas, capitales, unidades productivas agropecuarias, asociaciones de pequeños productores.

\section{The influence of associativity in the development of productive opportunities: the case of four agricultural associations in the Moquegua region - Peru}

\begin{abstract}
This article is based on the results of the diagnosis elaborated as part of the course «Field Practice» of Sociology of the Faculty of Social Sciences of the PUCP in the 2018-2 semester. It begins with a theoretical approach on associativity and small agriculture. A mixed methodology is proposed, collecting the perception of actors from the public, private and academic sectors, regarding the importance of this mechanism for the insertion of four agricultural associations of the Moquegua region in national and international markets. From the analysis of associativity and its relationship with capital - human, social, natural, physical, and financial - it is concluded that it functions as a driver of productive opportunities, but still faces challenges to make it a real option in the strengthening of small producers in Moquegua. In particular for the associations studied, natural capital (water or land) is a key factor for associativity, tradition and culture (social capital) serve as ties that foster trust in the group, and market opportunities supported by external agents that enhance the willingness to cooperate and associate. Finally, the institutional framework and the management capacity of these
\end{abstract}

1 Este curso forma parte del Plan de Estudios de la Especialidad, en el cual los estudiantes tuvieron un rol protagónico en el levantamiento, procesamiento y análisis de la información. Posteriormente, este trabajo fue profundizado entre los docentes del curso y un grupo de estudiantes, logrando como resultado el Cuaderno de Trabajo $\mathrm{N}^{\circ}$ 51. La influencia de la asociatividad en las oportunidades productivas: el caso de cuatro asociaciones agropecuarias en Moquegua: http://departamento.pucp.edu. pe/ciencias-sociales/novedades-departamento/cuaderno-de-trabajo-51-la-influencia-de-la-asociatividad-en-las-oportunidades-productivas-el-caso-de-4-asociaciones-agropecuarias-en-moquegua/ 
economic units will be decisive for considering associativity as a sustainable and development strategy for small producers.

Keywords: associativity, small producers, productive opportunities, capital, agricultural productive units, associations of small producers.

\section{INTRODUCCIÓN}

La actividad agropecuaria nacional es un sector poco atendido por los tomadores de decisiones. Del lado del gasto público, la inversión en el sector ha sido baja en el período comprendido entre los años 2000-2010, donde se verifica una disminución pese a que su participación en el PBI aumentó (Banco Mundial, 2017). Esta realidad, no quita el potencial que tiene el sector tanto en lo económico, social y lo ambiental, que le permite adquirir un papel protagónico en el desarrollo del Perú.

Un cuarto del total de la población económicamente activa (PEA) se sustenta en la agricultura (Instituto Nacional de Estadística e Informática [INEI], 2019). Sumado a lo señalado, actualmente hasta el $80 \%$ de productores, en al menos ocho regiones del país, se dedican a actividades agropecuarias (INEI-ENA, 2016). La agricultura familiar, definida como la producción en pequeña escala, ha registrado para el caso peruano un 57\% de pequeños productores que tienen más de 45 años (Minagri, 2015). En el caso de Moquegua, para 2018 se registró que solo el 7\% de productores agropecuarios pertenece a alguna asociación, cooperativa o comité de productores, según la Encuesta Nacional Agropecuaria 2018.

Los pequeños productores o unidades agropecuarias estudiadas se reúnen en torno a asociaciones. Las asociaciones estudiadas evidencian desinformación respecto de las reglas del mercado interno y externo, limitaciones para la exportación, poco conocimiento de cadenas productivas y de los procesos necesarios para incrementar la productividad en economías pequeñas como son la agricultura familiar. $\mathrm{Al}$ respecto, el presente estudio busca profundizar cómo la asociatividad se convierte en una estrategia de vida entre los pequeńos productores para incrementar su productividad y, en consecuencia, insertarse y consolidarse en el mercado local, regional, nacional e internacional.

Existe una gran diferencia en el desarrollo de la agricultura en zonas de la costa, selva y sierra. Mientras la costa presenta un amplio desarrollo que permite la exportación y estandarización, la selva tiene su enfoque en el desarrollo de la innovación y nuevas técnicas de cultivo, mientras que la sierra se encuentra relativamente estancada (Banco Mundial, 2017). A la necesidad de profundizar en el quehacer del pequeño productor se suma la complejidad de conocer la zona en donde este se desenvuelve y cuánto este entorno influye en su desarrollo. 
La región elegida para realizar el estudio es Moquegua, ubicada en el sur del país. Si bien tiene uno de los territorios con menor población a escala nacional, la diversidad de su geografía la convierte en una región clave. Este abarca desde la subregión costa hasta la subregión sierra, pasando desde los $13 \mathrm{msnm}$ hasta los $4600 \mathrm{msnm}$. Además, presenta una característica que puede replicarse en otras regiones, pues pese a que la agricultura es una de las principales fuentes de ingreso ( $27 \%$ de la población tiene como fuente al a agricultura) es la que tiene el menor PBI per cápita sectorial (gobierno regional de Moquegua, 2013). Estos puntos contrastan con el desarrollo que Moquegua llegó a conseguir en los últimos años y que la posicionó entre una de las tres regiones con el mayor Índice de Competitividad Regional del Perú (INCORE, 2018), siendo las otras dos regiones Lima y Arequipa. Dicho índice pone a Moquegua en una posición interesante, pues se evidencia la existencia de un entorno socioeconómico (infraestructura, salud, educación, mercado laboral y marco institucional) que impulsa el desarrollo de la productividad de las grandes y pequeñas empresas. Este contexto les permite utilizar de manera eficiente factores productivos tales como recursos humanos, capital físico, recursos financieros y tecnología. Tal escenario lleno de contrastes invita a estudiar cómo se encuentran las asociaciones de pequeños productores frente al desarrollo y aprovechamiento de oportunidades productivas.

El entorno agropecuario de la región, según el IV Censo Nacional Agropecuario 2012, se caracteriza por contar con un total de catorce mil unidades agropecuarias, las cuales representan el 0,006\% del total en el país. Asimismo, el 6,9\% de la superficie total de Moquegua es agrícola. Es decir, la región cuenta con un total de 14186 productores, de los cuales el 64\% se encuentra como participante de al menos una comisión; por ejemplo, la comisión de regantes.

Para el análisis del acceso a las oportunidades productivas en el contexto de la región Moquegua, se seleccionaron cuatro asociaciones de pequeños productores ubicadas en la provincia de Mariscal Nieto. Asimismo, para el desarrollo de la investigación, se optó por un diseño metodológico de carácter mixto, el cual consiste en aplicar herramientas tanto cualitativas como cuantitativas. También se realizaron entrevistas a agentes claves que permiten ampliar el conocimiento y la información del escenario en el que las asociaciones se desenvuelven. Se complementarán los resultados con información recopilada por la Encuesta Nacional Agropecuaria 2017.

A partir de lo señalado, el presente artículo inicia con una aproximación teórica a la asociatividad y a la pequeńa agricultura; luego de ello, se desarrolla la metodología y la percepción de actores del sector público, privado y académico respecto a la importancia de la asociatividad para la inserción en mercados nacional e internacional. Después, se profundiza en la situación del pequeño agricultor frente al trabajo colectivo a partir de los cuatro casos seleccionados para, finalmente, concluir 
con las reflexiones sobre la asociatividad como una estrategia de vida impulsora de oportunidades productivas.

\section{LA ASOCIATIVIDAD Y PEQUEŃA AGRICULTURA: UNA APROXIMACIÓN TEÓRICA}

En América Latina, y en el Perú en particular, existen diversos mecanismos de cooperación, con mayor incidencia entre familias en zonas urbano-populares ${ }^{2}$, comunidades andinas y amazónicas, en donde este se convierte en el factor clave para su sobrevivencia y crecimiento en entornos naturales y socioeconómicos difíciles y complejos, imposibles de dominar y transformar si no se coopera.

La reciprocidad y el intercambio de favores que subyace estas relaciones de cooperación han significado la diferencia entre morir o vivir y, en consecuencia, adaptar, utilizar y reproducir los medios de vida disponibles en dichos contextos. En ese sentido, el trabajo colectivo en zonas urbanas —el ayni o el ayllu en el mundo andino y prácticas comunitarias de las diversas etnias amazónicas - nos presenta distintas e innumerables evidencias de lo que significa mantener una economía para subsistir y desarrollarse como sociedad y como cultura (De la Torre \& Sandoval, 2004; Temple, 2008; Gómez, 2016; Vega Centeno, 1992).

Esta tradición social de los pequeños y medianos pueblos urbano-populares, andinos y amazónicos es la que ha llevado a interpretar para algunos científicos sociales que la cooperación y la reciprocidad reproducida en el trabajo productivo de carácter comunal expresa acciones concretas de solidaridad, respeto y colaboración basado en valores orientados por la preocupación hacia el otro y el compromiso con el prójimo (Flores Galindo, 1988; Golte, 1980; Golte \& Adams, 1990).

Por el contrario, también se considera que esta imagen del trabajo comunal de carácter productivo tiene más bien connotaciones «románticas», «idealistas» y hasta ideológicas para justificar la existencia de un socialismo "fáctico» incrustado en las costumbres de dichos pueblos y sus formas de producción basado en la reciprocidad (Golte \& De la Cadena, 1983; Golte, 1992).

Diversos estudios muestran que en el mundo comunal existen desigualdades económicas y de poder y que las prácticas colectivas pasan más bien por un filtro racional costo-beneficio, motivado por intereses particulares - y hasta egoístas-, debido a la toma de conciencia de los pobladores en la cual su reflexión asume que

\footnotetext{
2 Espacios o zonas urbano-populares son «el resultado del funcionamiento y la coordinación de dos lógicas: la del mercado y la del Estado, pero también de una tercera: la lógica de la necesidad (Abramo, 2012). Esta necesidad, encarnada en las personas que habitan tales asentamientos, ha consistido en habilitar progresivamente el espacio conquistado, de tal manera que lo que originalmente era cerro, arenal, tierras eriazas, bosques o zonas residuales se convierta en parte de la ciudad ante la falta de habilitaciones urbanas por el Estado o del mercado formal (Riofrío \& Driant, 1987)» (Velarde, 2017).
} 
el único camino para sobrevivir es trabajar bajo modelos colectivos, porque los individuales son considerados ineficaces para enfrentar las contingencias de entornos geográficos sumamente adversos y accidentados (Diez, 2006 y 2014; Urrutia, Remy $\&$ Burneo, 2019). Es más ventajoso participar en dicha faena comunal que no formar parte de ella pues mi esfuerzo individual conllevaría un doble sacrificio que a la larga perjudicaría a mi familia y traería pocos beneficios (Axelrod, 1986 y 2003).

Ambas lógicas — solidaria y utilitarista - podrían convivir, pero lo cierto es que los ámbitos de acción en la cual se desenvuelven los individuos, sus necesidades y motivaciones delimitarán los énfasis de cada una de estas racionalidades en desmedro de la otra. En dicho contexto social, surge el debate académico de cómo se ubicaría teóricamente la categoría asociatividad y cuál es su capacidad y relevancia para explicar el mundo económico rural o urbano-popular basado en costumbres no occidentales como la reciprocidad y la cooperación.

¿Hasta qué punto es relevante ubicar a esta asociatividad dentro del trabajo que realizan las cooperativas o las empresas comunales rurales cuando su constitución legal exige la participación comprometida de todos sus miembros y el cumplimiento de normas de cooperación coercitiva y hasta coactiva por decisión de todos los que se agrupan bajo estas modalidades organizacionales?

Por otro lado, aunque sería materia de otra investigación, ¿̇cuán pertinente es hablar de asociatividad en el mundo orientado por el altruismo, el servicio hacia los demás, o el voluntariado en el campo de las organizaciones no lucrativas como las fundaciones o las ONG, e inclusive entre las entidades públicas, donde cooperar es un medio fundamental para garantizar los resultados de inclusión, equidad y paz social?

Pareciera entonces que la asociatividad está presente como una oportunidad o alternativa de solución en todos los campos de la acción colectiva organizada, pues esta requiere participación, compromiso, esfuerzo compartido, pero sobre todo confianza en las reglas de juego que orientan las relaciones sociales de individuos que consideran que solo agrupándose pueden alcanzar objetivos de diversa índole. La asociatividad puede ser considerada un medio estratégico que está a disposición de todo grupo social que hace uso de este constructo cualquiera sea la finalidad que se proponga obtener (política, económica, sociocultural, altruista, delictiva, entre otras).

Los grupos o líderes de diversas entidades evalúan que en determinadas situaciones complejas se requiere el trabajo asociativo. Aliarse con otros es más eficaz que el trabajo individual o hecho de manera particular (Mamani, 2017). Sin embargo, una corriente desde la perspectiva de las ciencias sociales indicaría lo contario, puesto que el interés particular y egoísta primaría antes que cualquier intención de asociarse: las personas se asocian luego de haber agotado todas las opciones posibles 
de trabajo familiar o individual y calculado que de otra forma les sería imposible alcanzar el resultado (De Remes, 2001).

La relevancia de la opción por asociarse radicaría entonces en el tipo de problemas que se quieren resolver y la evaluación de los recursos con los que cuentan los posibles asociados. Las familias o pequeñas unidades productivas perciben y evalúan con quién debieran asociarse de acuerdo con los capitales con los que cuentan y los objetivos principalmente económicos que esperan alcanzar.

Esta es la razón principal que justifica, motiva y permite a los miembros integrantes asumir el costo de aliarse momentánea o permanentemente. En nuestro caso estamos hablando de organizaciones de productores agrícolas cuyas finalidades para asociarse y cooperar son en principio lucrativas, donde la rentabilidad económica es un factor fundamental para evaluar si es viable o no el trabajo colectivo.

\section{¿Qué se entiende por asociatividad? A manera de balance}

La asociatividad puede definirse como una estrategia de colaboración entre empresas de similares características — que mantienen su independencia jurídica y gerencial - con la finalidad de sumar recursos y cubrir debilidades para lograr un objetivo estratégico común (Domínguez \& Ulloa, 2016; Ministerio de la Producción del Perú; Vegas, 2008). Algunos autores resaltan especialmente el rol de las pymes y de los productores. Por ejemplo, Del Valle (2013) define la asociatividad como un mecanismo de cooperación entre productores o empresas pequeñas y medianas, donde cada uno de los participantes decide participar en un esfuerzo conjunto por un objetivo colectivo (p. 18). En otras palabras, el concepto de asociatividad se refiere a la cooperación de grupos por un objetivo compartido y beneficio común (Brasier et al., 2007; Devaux, 2006; Ruiz, 2001).

Otras definiciones entienden a la asociatividad como una estrategia de colaboración colectiva o de coaliciones empresariales que persigue la creación de valor y busca superar la escasez de escalas individuales para incrementar la competitividad a partir de la concreción de objetivos comunes (López \& Calderón, 2006; Lozano, 2010).

Asimismo, otra definición pone el peso en la defensa de intereses económicos y del bienestar del asociado y su familia para participar voluntariamente en el colectivo, pero la base de la decisión parte de intereses particulares (IICA, 2004). Por otro lado, la asociatividad se entiende como un indicador de desarrollo y existencia de capital social dependiendo del marco institucional en el cual se ubican los integrantes de la unidad económica-productiva (Mamani, 2017).

Hay una riqueza en la variedad de las distintas definiciones que se abordaron sobre asociatividad. A continuación, se presenta el resumen de los énfasis conceptuales que cada autor prioriza para analizar este fenómeno social: 


\section{Definiciones sobre asociatividad}

Actividad realizada dentro de una asociación, cooperativa u otra figura jurídica que agrupa a los productores [...] y que evidencia, por un lado, la gestión de objetivos en beneficio de la producción [...], su transformación, comercialización [...] incluye la mejora de las condiciones socioeconómicas y los relacionamientos productivos de dichos productores, así como el mejoramiento de sus instituciones, situaciones que en su conjunto pueden ser considerados como indicadores de desarrollo rural (Mamani, 2017).

Este mecanismo se entiende como una estrategia de colaboración colectiva que persigue la creación de valor a través de la concreción de objetivos comunes que contribuyen a superar la escasez de escalas individuales y a incrementar la competitividad, herramienta que es necesaria para la supervivencia de las pequeñas y medianas empresas (Lozano, 2010).

Representan una acción colectiva de productores con intereses productivos y comerciales comunes que compiten pero que también cooperación para identificar y obtener beneficios económicos para todos sus miembros (Brasier et al., 2007; Devaux et al., 2006).

Tienen como objetivo incrementar la producción y rentabilidad de la actividad agropecuaria, así como también mejorar las capacidades y habilidades de sus miembros (Karami et al., 2005).

[...] combina el trabajo individual/familiar de la finca con el esfuerzo colectivo en alguno o varios aspectos para hacer negocios en común. Esta forma mixta es muy interesante, pues respeta el orgullo de la propiedad como una característica cultural muy fuerte en el campesino latinoamericano. De ese modo se puede seguir administrando la propiedad familiarmente, decidiendo qué hacer, organizando a su modo la parcela y disponiendo de la mayor parte de su fuerza de trabajo. Lo que integra en la empresa es alguna fase del proceso o alguna actividad secundaria. Pero también es posible [...] pensar en empresas asociativas donde se comparta todo el proceso e inclusive se asocien los recursos, la toma de decisión y todos los trabajos de producción-procesamiento-comercialización (IICA, 2004).

Como una estrategia resultada de una cooperación o coalición de empresas en función de un objetivo en común, en la que cada participante mantiene independencia jurídica y gerencial (López \& Calderón, 2006).

Mecanismo de cooperación entre organizaciones en donde cada una mantiene su independencia jurídica y autonomía gerencia, decidiendo voluntariamente participar en un esfuerzo conjunto con los otros participantes para la búsqueda de un objetivo común (Ruiz, 2001).

La definición conceptual que orienta la presente investigación entiende a la asociatividad como un constructo social basado en relaciones de cooperación y confianza entre sus miembros, los cuales están motivados por la necesidad de conseguir mayor poder y capacidad para acceder a espacios o recursos considerados valiosos permitiéndoles alcanzar objetivos principalmente económicos, pero también de 
orden social y político. Este mecanismo de cooperación podrá tener mayor fuerza dependiendo del marco institucional en el cual se desenvuelvan y de la confianza que tengan en las reglas que acuerden para generar mayor predictibilidad y obtener beneficios individuales, familiares o colectivos.

\section{La asociatividad en la práctica}

Estudios realizados sobre la asociatividad en un contexto latinoamericano se enfocan en las ventajas que esta proporciona. El Centro de Exportaciones e Inversiones (CEI) Nicaragua (2010) afirma que la asociatividad incrementa la producción y productividad, mejora el acceso a nuevos mercados, brinda mayor poder de negociación, mejora el acceso a tecnologías de productos y a financiamiento, reduce los riesgos y costos, mejora la calidad y la gestión del conocimiento técnico (diapositiva 28, pp. 3-4). De igual manera, el Departamento Nacional de Planeación de Colombia ha identificado la asociatividad como un factor clave para mejorar la calidad de vida en el ámbito rural (SAC, 2013, p. 11).

Existen múltiples estudios dedicados al análisis de los beneficios de la asociatividad rural en Colombia que pueden servir como una base para ilustrar el contexto peruano dada las similitudes entre dicho contexto y el colombiano. El estudio de Melo, Melo y Fonseca (2017) muestra cómo, debido a la asociatividad, los miembros de la asociación de pequeños caficultores de Ocamonte (APCO), en el departamento de Santander en Colombia, pudieron lidiar con la crisis del café de las décadas de 1980 y 1990, estar asociados por más de veinte años, así como obtener certificaciones de comercio justo por la Fair Trade Labeling Organization (FLO) y de productos orgánicos. A su vez, estas certificaciones han impulsado el agroturismo y visitas académicas de diferentes universidades locales, generando beneficios socioeconómicos y ambientales para la comunidad en general (Melo et al., 2017, pp. 541-542).

Según Mejía López (2013), presidente de la Sociedad de Agricultores de Colombia (SAC), la asociatividad mejora el acceso a nuevos mercados, la formalización del trabajo, el desarrollo de capacidades empresariales, la productividad de los alimentos y la calidad de vida de la población rural (p. 5). Asimismo, Del Valle (2013) — director de SAC — afirma que la asociatividad ayuda con la estandarización de la producción, negociación directa, tecnificación, mayor acceso a programas gubernamentales, mejora la calidad de vida, disminuye los costos de producción y proporciona mejores precios (p. 18).

El Estado peruano también ha realizado estudios que recalcan los beneficios de la asociatividad para los pequeños productores. Según el Ministerio de la Producción del Perú (s.f.), la asociatividad brinda las ventajas y oportunidades para las mipyme, como por ejemplo, el ingreso a nuevos mercados, el desarrollo de nuevos 
productos y servicios, economías de escala y la generación de fortalezas frente a grandes competidores (p. 20).

La mayoría de los estudios en un contexto peruano analizan los beneficios de la asociatividad agraria. El estudio de Azula (2015), que estudia a los pequeños agricultores algodoneros del valle de Pisco, concluye que la asociatividad reduce la incertidumbre de los pequeños productores y genera beneficios con respecto a la escala de producción, compra de insumos, negociación de precios, acceso a financiamiento y acceso a compradores (pp. 166-167).

Otros estudios aportan una mirada crítica a la asociatividad rural al exponer y evaluar las posibles desventajas para los pequeños productores. En el ámbito peruano, Salas (2017) muestra que, para los pequeños productores, la asociatividad se relaciona negativamente con las ventas en el mercado nacional, ya que no cuentan con los mismos recursos que tienen los medianos y grandes productores (p. 49). El CEI de Nicaragua (2010) es más preciso en su análisis e identifica que muchos de los pequeños productores no reciben un buen precio en el mercado local debido al límite de productos que las asociaciones pueden ofrecer (p. 4).

En esa perspectiva, algunos autores evalúan la veracidad del argumento de que la asociatividad inherentemente proporciona ventajas a sus miembros. Por ejemplo, el estudio de Toledo (2016) muestra que la política asociativa per se no garantiza ninguno de los beneficios que ofrece, ya que la asociación de Talpuy no pudo conseguir mejores ingresos, mejor capacidad ni oportunidades de negociación con mercados nacionales o internacionales para sus miembros (p. 7).

Ferrando (2015) identifica como causas importantes del fracaso de la asociatividad la desconfianza y la falta de educación que impide el conocimiento necesario de técnicas, gerencia y del mercado internacional. Vegas (2008) también se enfoca en la falta de objetivos comunes definidos, la falta de procedimientos de control y de transparencia como factores que dificultan la asociatividad. Según Ferrando (2015), la esperanza de ayuda del Estado y el rechazo de la asociatividad son otros factores que dificultan la asociatividad de los pequeños productores agrícolas (p. 185).

Asimismo, Fairlie (2008) argumenta que el tamaño pequeño de la tierra, las deficiencias relativas a las condiciones del cultivo y factores institucionales también dificultan la asociatividad de los pequeños agricultores.

A pesar de las críticas sobre la viabilidad o no de la asociatividad, estudios realizados - tanto en el Perú como en otros países de América Latina— han identificado ciertos factores que son importantes para su éxito. El Ministerio de la Producción del Perú, Domínguez y Ulloa (2016) y el CEI de Nicaragua (2010) han determinado que la confianza es un elemento clave para el éxito de la asociatividad. Suárez y Suárez (2017) analizan la importancia del conocimiento para el éxito de las asociaciones. 
Según el estudio, mientras el individuo participante tenga más conocimiento, tendrá una mayor disposición a la asociatividad (Suárez \& Suárez, 2017, p. 94). Fairlie (2008) analiza la importancia del comercio justo para la asociatividad rural: su estudio muestra que el comercio justo favorece a las asociaciones de productores de banano orgánico en Piura.

Asimismo, el Ministerio de la Producción del Perú menciona las siguientes buenas prácticas para la asociatividad: la elección de los asociados, el cumplimiento de los compromisos y la gestión de la modalidad asociativa (p. 24). Domínguez y Ulloa (2016) también identifican la cercanía geográfica y la cultura de colaboración como factores importantes que facilitan la asociatividad (p. 113). Según el CEI (2010), otros factores importantes para el éxito de la asociatividad son la transparencia, un objetivo común, una planificación adecuada, buen liderazgo, ejecución de proyectos que ayuden a conseguir financiamiento económico y la resolución de desacuerdos (p. 5).

Según Paredes y Fort, para que la asociatividad pueda funcionar sostenidamente se deben tomar en cuenta dos dimensiones: (i) los determinantes para asociarse o no en una iniciativa económica-productiva, y (ii) el impacto en la productividad y los mecanismos que lo permiten. Respecto de la primera dimensión, en los «determinantes» son claves las estructuras específicas de articulación, así como los costos de transacción que los productores enfrentan para poder articularse, y las restricciones de entrada basadas en condiciones para la producción. Para la dimensión de «impacto en la productividad», los autores proponen que existen resultados mixtos con relación al impacto económico de la articulación de medianos y pequeńos productores a las cadenas de valor.

Con el reconocimiento de los beneficios de la asociatividad, surge la importancia de prestar atención a las variables o circunstancias que pueden impulsar el desarrollo del sector agrario, puesto que, si la asociatividad no es analizada y su funcionamiento no es atendido, se puede convertir en un limitante para que los pequeńos productores elijan cultivos más rentables (Gobierno Regional de Moquegua, 2013).

\section{Sobre los determinantes de la asociatividad}

Con respecto a las estructuras específicas de articulación, existe un conjunto de requisitos que las unidades productivas deben tener para acceder a la asociatividad y, por lo tanto, a las cadenas de valor. Estos se refieren a una escala mínima de tenencia de tierra, al acceso a riego, a la asistencia técnica, entre otros, de tal manera que puedan mejorar su negociación en los mercados. Sobre los costos de transacción, se señala que la asociatividad y la inclusión en las cadenas productivas puede disminuirlos en la medida que tengan acceso a información de mercados, capacitación y apoyo de actores del entorno, en especial las grandes o medianas empresas, 
ya que estas tienen un mayor conocimiento del entorno comercial. Finalmente, sobre las restricciones de entrada para asociarse, se vinculan principalmente a la base mínima de activos con los que cuentan los pequeños productores, donde las características sociodemográficas como edad, educación, activos del hogar, así como la ubicación y el contexto, resultan claves para poder formar parte de la asociación y, por lo tanto, de la cadena de valor (Paredes \& Fort, 2018).

Entre otras restricciones que pueden limitar la entrada de la asociación a la cadena de valor se encuentran: acceso al crédito, acceso a información de mercados y mecanismos de comercialización, nivel de tecnología, capacidad de producción y productividad, cultura empresarial y organizacional, ampliación de la frontera agraria y utilización de recursos hídricos, entre otros (Gobierno Regional de Moquegua, 2013).

\section{Sobre los impactos en la productividad y los mecanismos que lo permiten}

Los impactos de la asociatividad están orientados principalmente al incremento de la productividad — dependiendo de la tecnología y el acceso a mercados- y el consecuente aumento de los ingresos de los productores. Estos se diferencian y pueden tener diversos resultados según el tipo de cultivo, precio y mecanismos como el acceso al crédito, esquemas de contratos, certificación, asistencia técnica o mano de obra, entre otros (Paredes \& Fort, 2018; Minot \& Sawyer, 2014). Todos estos mecanismos contribuyen a disminuir la natural aversión al riesgo, especialmente de los pequeños productores, debido al manejo de información colectiva, insumos, tecnología y negociación en mejores condiciones para determinados mercados reduciendo su incertidumbre. "La agricultura por contrato puede verse como una forma para combinar las ventajas de la producción a gran escala con las fortalezas de la producción a pequeña escala» (Minot \& Sawyer, 2014).

La ausencia de estos mecanismos aumenta los riesgos para que la asociatividad y su incursión en la cadena de valor disminuyan los impactos en la productividad, y por lo tanto, en los ingresos. Entre dichos riesgos destacan la rigidez para el cumplimiento de estándares de producción, los juegos de poder asimétricos para las negociaciones entre productores y compradores, contratos con requerimientos alto nivel de insumos, tecnología y tiempos de cumplimiento- que sobrepasan la capacidad de los productores para invertir en ellos (Vargas \& Fort, 2018).

Complementando las dimensiones de los determinantes para la asociatividad y los impactos en la productividad, es relevante analizar también el marco institucional que da soporte e incentiva la acción colectiva organizada. Asimismo, se debe analizar la capacidad de gestión de los líderes de las asociaciones donde los mecanismos de toma de decisiones, coordinación de funciones, asignación de responsabilidades desde una perspectiva empresarial serán también parte de los mecanismos centrales 
para que la asociatividad aspire a ser sostenible. ¿Puede este análisis complementarse desde otra perspectiva que se sume al enfoque de los determinantes de la asociatividad y al impacto que aspiran lograr con la productividad? Una entrada desde los activos o capitales podría explicar los factores que promueven o motivan la asociatividad y su viabilidad entre los pequeños productores agrícolas.

\section{Los capitales como medios de vida para la reproducción de la asociatividad}

Existe un consenso académico sobre la importancia que tiene el acceso, control y uso de diversos recursos que poseen los individuos al momento de buscar salidas ante las dificultades que les presenta el entorno en el cual interactúan. En ese sentido, desde finales de la década de 1980, instituciones como el DFID ${ }^{3}$ promovieron el Enfoque de Medios de Vida Sostenibles, donde los capitales tienen un rol importante para la subsistencia y desarrollo de las comunidades rurales [Chambers \& Conway (1991), Bebbington (1999), DFID (1999) y WFP (2001), citados por Stoian \& Donovan (2010)].

Un medio de vida comprende posibilidades, activos (incluyendo recursos tanto materiales como sociales) y actividades necesarias para ganarse la vida. Un medio de vida es sostenible cuando puede soportar tensiones y choques y recuperarse de los mismos, y a la vez mantener y mejorar sus posibilidades y activos, tanto en el presente como en el futuro, sin dañar la base de los recursos naturales existentes (Miranda, 2003, p. 35) (López, Bedoya Patiño \& Cárdenas Grajales, 2015, p. 203).

Según DFID, el enfoque de medios de vida analiza los hogares rurales a partir de los recursos o activos que poseen y a los cuales denomina capitales. Existen cinco tipos de capitales: humano, social, natural, físico y financiero. «Un capital es entendido como un recurso invertido para crear nuevos recursos a largo plazo, una estrategia de vida es la forma como los hogares utilizan sus activos y dotación de capitales» (DFID, 1999).

El capital humano se refiere a las capacidades y habilidades y desarrollo biológico de los individuos para relacionarse con el entorno. El capital social corresponde a las redes de soporte institucional, relaciones de confianza entre individuos y en las reglas que orientan su acción. El capital natural corresponde a la apropiación y manejo de recursos como el agua, la tierra, la biodiversidad, condiciones ambientales, etc. El capital físico referido a la infraestructura pública y privada de la cual disponen para satisfacer sus necesidades básicas y desarrollo productivo. Finalmente,

\footnotetext{
3 Ministerio de Desarrollo Internacional (DFID por sus siglas en inglés) es el órgano del gobierno del Reino Unido responsable de administrar la ayuda exterior. El objetivo del DFID es "promover el desarrollo sostenible y eliminar la pobreza mundial».
} 
el capital financiero considera el ahorro, créditos, inversiones, impuestos, entre otros, y es clave para las actividades económicas.

Si bien la literatura de las ciencias sociales reconoce que el control y uso de capitales son centrales como medios de vida que las familias rurales puedan subsistir y desarrollarse, el objetivo es conocer cómo los utilizan al momento de decidir y poner en marcha el trabajo asociativo. ¿Qué factores pueden influir para que la estrategia colectiva sea priorizada frente a la salida individual? ¿En qué condiciones algunos capitales son más importantes que otros? El hecho de asociarse no es una opción «natural»: es una construcción social que implica un costo (tiempo y dinero) para las familias.

Los individuos y sus familias que toman la decisión de agruparse con otros para alcanzar objetivos de rentabilidad económica - ya sea por iniciativa de estos o motivados por un agente público o privado externo al colectivo- ponen a disposición de los otros integrantes los medios de subsistencia que poseen para ser considerados como aliados y tener una garantía que permita verificar que sus recursos suman y generan valor simbólico o tangible al grupo. Si bien los intereses en común son fundamentales, puesto que la problemática a resolver afecta casi por igual a todos los interesados, para que la asociatividad se produzca y mantenga en el tiempo es necesario saber que los futuros miembros tienen la capacidad de aportar al colectivo y respetar las reglas que se generen como resultado de esta asociación.

Los intereses en común no son suficientes si no se sustentan en los activos que proporcionan las personas o familias para evaluar que el trabajo conjunto los hace más fuertes comparados con el esfuerzo individual o fragmentado. Dichos medios de subsistencia representan la "garantía» de que sus activos (conocimientos, historia compartida, posición social, recursos que controlan, entre otros) son mínimamente iguales al de los otros interesados. Esto simboliza que los intereses en común y el camino de la colaboración mutua es viable, pero solo es posible si tienen confianza en los recursos que aportan y en las reglas de juego que orientarán su acción.

Varias de las razones por las cuales los pequeños productores agrícolas en la costa y sierra peruana no desean asociarse y trabajar de manera conjunta en actividades productivas se relacionan con la desconfianza que se ha generado entre ellos mismos como consecuencia de factores de índole personal, subjetiva y cultural que se manifiestan en su vida cotidiana, así como históricos por la violencia política en la época del terrorismo u otros vinculados a la parcelación y distribución de las tierras durante el gobierno de Alberto Fujimori.

La importancia del control y uso de los recursos tangibles e intangibles permite incrementar el poder de los individuos en su entorno social. Si dichos recursos se juntan con otros activos, se acrecienta dicho poder. En el campo de la asociatividad con fines económicos esto es central y muy diferente de la cooperación 
que se desarrolla en otros ámbitos de acción. Por ejemplo, el político-partidario o el de las políticas públicas que manejan bienes comunes o colectivos, e incluso el del mundo altruista o filantrópico que promueven diversas organizaciones de la sociedad civil, incluyendo a los movimientos sociales. Es en dichos ámbitos donde se evidencia el dilema del polizonte o free rider: aquel que se beneficia del trabajo de los demás debido al acceso ilimitado sobre los bienes comunes que por su naturaleza no se puede impedir el uso o beneficio a aquellos que no cooperan en su mantenimiento y reproducción. En el caso de las unidades productivas con fines de lucro, este dilema en principio no debería presentarse, pues el bien que manejan es exclusivo del grupo que se asocia; sin embargo, como se ha señalado anteriormente, la asociatividad presenta límites en la racionalidad costo-beneficio debido a que son los intereses o expectativas particulares los que primarán sobre los colectivos, a no ser que los miembros que se asocian perciban lo contrario (Tanaka, 2001 y Olson, 1992).

\section{Metodología}

Para desarrollar el estudio, se aplicó un diseño metodológico de carácter mixto, es decir, una técnica que hace uso de herramientas tanto cualitativas como cuantitativas, de modo que pueda valorarse la representatividad de los datos recolectados, ahondar en la subjetividad de los individuos entrevistados, y sus percepciones y juicios. El uso de métodos mixtos para una investigación facilita un mejor entendimiento del fenómeno que estamos estudiando, pues implica hacer una recolección, análisis e integración de datos tanto cuantitativos como cualitativos, así como análisis empíricos y críticos para elaborar inferencias sobre la realidad a partir de la información recogida (Hernández-Sampieri \& Mendoza, 2014).

Se seleccionaron cuatro asociaciones de pequeños productores, ubicadas en la provincia de Mariscal Nieto. Estas son:

- Asociación Pioneros de San Cristóbal

- Asociación de Productores Agrícola y Exportadores de Moquegua - APAEXMO

- Asociación de Vitivinicultores de Moquegua - AVIMO

- Asociación de productores de Cuy - ASPROCUY

Se realizaron entrevistas y encuestas diferenciadas a los integrantes de cada asociación; se diferencia entre dirigente y asociado. Se llegaron a aplicar encuestas a sesenta pequeños productores de un total de cien identificados. De estos, se entrevistó a nueve pequeños productores, priorizando a los que tienen un cargo en la Junta Directiva. 
De otro lado, se realizaron entrevistas a agentes clave cuya labor se encuentra relacionada con la que realizan los pequeños productores, y forman parte del entorno de las asociaciones. Se hicieron tres perfiles de agentes clave priorizando la procedencia. Bajo este criterio se entrevistó a doce agentes clave: sector público (cuatro), sector privado/consultores (cinco), y académico (tres).

Finalmente, se realizó un grupo focal con miembros de la asociación Pioneros de San Cristóbal, con el fin de recoger las percepciones e ideas de un gran número de productores y productoras. Se concluyó el trabajo con sesenta encuestas y veintiún entrevistas.

Cabe resaltar, que, si bien se llegó a encuestar a socios de cada una de las cuatro asociaciones, no fue posible encuestar a la totalidad por motivos de tiempo y disponibilidad de los miembros, además de la distancia considerable entre las propiedades de los socios. En ese sentido, elementos de carácter representativo se pondrán en diálogo con la Encuesta Nacional Agropecuaria 2018.

\section{Percepciones Sobre la importancia de la asociatividad POR aCtORES PÚBlicos Y PRIVADOS DE LA REGIÓN MOQUEGUA}

Como mecanismo para aproximarse a la vinculación entre la asociatividad y las oportunidades productivas de los pequeños productores en Moquegua, se realizaron once entrevistas a actores clave que desempeñan funciones en tres tipos de organizaciones: empresas privadas, sector público y sector académico, específicamente, instituciones educativas superiores. Véase la tabla 1 para más detalle sobre los actores entrevistados:

Tabla 1. Actores clave entrevistados

\begin{tabular}{llc}
\hline Sector & Institución & $\begin{array}{c}\text { Número de } \\
\text { entrevistas }\end{array}$ \\
\hline \multirow{3}{*}{ Público } & Gerencia Regional de Producción - Moquegua & 1 \\
& CITE Agroindustrial & 1 \\
& Ministerio de la Producción - Produce & 1 \\
& Municipalidad Provincial de Mariscal Nieto & 1 \\
\hline \multirow{2}{*}{ Privado } & Anglo American Compañía Minera & 3 \\
& Tecnocef & 1 \\
\hline \multirow{3}{*}{ Académicos } & Universidad Nacional de Moquegua - UNAM & 1 \\
& Centro de Formación Agrícola Moquegua & 1 \\
\hline
\end{tabular}


La información que brindaron los actores nos permite conocer la percepción de estos en relación a la gestión del agua, la asociatividad, productividad, comercialización y el rol de las instituciones en el proceso de consolidación del trabajo colectivo para el acceso a mejores oportunidades productivas.

\section{Gestión del agua}

Un tema fundamental en el que coincidieron los tres tipos de actores entrevistados (privados, públicos y académicos) fue la gestión del agua en la zona y su uso para fines agrícolas. Al respecto, uno de los entrevistados (Pablo, comunicación personal, 1-7 de octubre de 2018) destacó que la región Moquegua es abastecida por dos fuentes de agua: una que proviene de los ríos Torata, Tumilaca y Guaraná, y otra que se abastece de la desviación del canal de agua realizada por el proyecto Pasto Grande. Asimismo, señaló que la construcción del reservorio de agua albergaba inicialmente 210 millones de metros cúbicos, lo que generaba un apoyo significativo en las épocas de sequía; sin embargo, a la fecha ha reducido su capacidad a 140 millones. Precisó que la gestión del agua, en el caso de las asociaciones, se realiza mediante la junta de regantes, a la cual se le desembolsa el pago de una cuota por hora de uso y por hectárea al año. De esa manera, cada asociación recibe la cuota de agua correspondiente, la cual es supervisada por la autoridad local. Sin perjuicio de lo señalado, el entrevistado identificó lo siguiente:

[...] el agua es uno de los principales problemas acá en Moquegua, y ahora con el cambio climático, peor. Nosotros somos una zona muy vulnerable y estamos muy cerca al desierto de Atacama, somos una zona desértica (Pablo, comunicación personal, 1-7 de octubre de 2018).

$\mathrm{Al}$ respecto, cabe precisar que, si bien los entrevistados señalaron su preocupación por el agua, esta no se sustentaba en la falta de acceso al recurso, sino a la gestión ineficiente. En efecto, uno de los entrevistados señaló que el riego más empleado en la zona se da "por gravedad" y que el gran reto consiste en transitar hacia un riego tecnificado, ya sea por aspersión o goteo - dependiendo del cultivo-, que haga un uso más eficiente del agua. Los esfuerzos ya se han realizado, no obstante, aún no se encuentran operativas las hectáreas donde ya se ha transitado hacia un uso más eficiente del agua.

La repartición de agua funciona bien debido a que las asignaciones públicas vienen de ańos atrás, pero esto en tanto es riego por gravedad, el problema es cómo cambio de riego por gravedad a aspersión [...] pero yo no daría ni un sol más de inversión mientras no se pongan operativas las 150 hectáreas donde ya se invirtieron millones de dólares (Lalo, consultor privado, 1-7 de octubre de 2018). 
Otro elemento a considerar es el tipo de cultivo que se cosecha. Uno de los entrevistados (Lalo, consultor privado, 1-7 de octubre de 2018) señaló que el volumen utilizado para una hectárea de alfalfa frente al utilizado para un cultivo transitorio o perenne consiste en una diferencia significativa de hasta 11000 metros cúbicos al año. De forma adicional, el entrevistado precisa que una de las principales limitaciones para una gestión del agua más eficiente es el acceso a tecnologías en las parcelas; al respecto, precisa que, si bien se dispone de tecnología para implementar, en las parcelas se cuenta con infraestructura limitada para su implementación, la cual es aún más compleja para poder acceder considerando el tiempo y costos económicos que implica su instalación.

A lo descrito debe agregarse la gestión informal del agua. Uno de los entrevistados identificó que "[...] también sucede que llega un repartido y alguien necesita dos horas más, entonces arregla por otro lado...» (Lalo, consultor privado). Estos casos no son aislados; por el contrario, se ha vuelto una regla institucionalizada que los entrevistados identificaron como uno de los problemas que sostiene aún la inadecuada medición del uso del recurso hídrico en la zona.

A partir de lo señalado, se observa que la débil gestión en el agua, así como la preocupación colectiva sobre su uso, ha impactado, mediante la generación de incentivos, en los pequeños productores de modo que se asocien con el objetivo de lograr una gestión suficiente y eficiente del recurso para sus cultivos. El capital natural, que se percibe como escaso y en riesgo de agotarse, comprende un importante incentivo para la asociación. La necesidad de acceder a este recurso varía dependiendo de los productos que los pequeños productores deseen cultivar; no obstante, ya se han identificado casos de asociaciones, tales como APAEXMO y AVIMO, que tienen grandes incentivos para asociarse, toda vez que requieren grandes cantidades de agua para su producción y esta no se está gestionando de forma adecuada.

\section{Asociatividad}

A diferencia de la gestión del agua, las opiniones de los actores clave entrevistados se encuentran divididas en lo que respecta a la asociatividad. Por un lado, están quienes consideran que la asociatividad se encuentra en débiles condiciones debido a la gran cantidad de minifundios en la zona; por otro, quienes identifican una ausencia en el enfoque empresarial. Si bien todos coinciden en la importancia del rol de la asociatividad para el acceso a mejores oportunidades productivas y para la consolidación de los grupos de pequeños productores, no todos están de acuerdo sobre la situación vigente de ella en la región. En referencia a la primera posición, uno de los actores académicos identifica que en la región la gran mayoría de tierras son «minifundios» $\mathrm{O}$ «miniparcelas»: 
[...] esto es lo que no permite de que pueda haber volumen de producción. Cuando hablamos a nivel de empresa, la asociatividad va a ayudar agregar volumen a la producción y poder ingresar a un nuevo mercado. E ingresar a un nuevo mercado y poder tener ventas constantes. Y a la vez también se va a reducir los costos de producción, se va a reducir también quizás... va a haber mayor presencia del productor en mercados competitivos o ferias, uno solo no lo puede hacer, pienso yo al respecto (Omar, ingeniero de un instituto educativo de Moquegua).

En efecto, actores del sector privado coinciden con este aporte, y complementan que «[...] los agricultores tienen un perfil más de emprendedor individual, ellos podrían funcionar bien si quisieran formar una empresa, pero no quieren complicarse... son más emprendedores individuales que socios...» (Iván, trabajador de empresa privada en Moquegua). Al respecto, actores del ámbito privado coinciden en que la asociatividad, actualmente, no funciona ni contribuye de la manera en que los propios agricultores esperan; principalmente, se utiliza como un espacio para acceder a concursos y oportunidades para adquirir financiamiento y apoyo de diversas instituciones. Además, resaltan que uno de los principales problemas por lo que la asociatividad no se encuentra tan masificada e institucionalizada en la zona es una gran falta de confianza entre los productores: las personas tienen miedo a perder su capital financiero. Asimismo, identifican que la desconfianza también se encuentra presente en su propia percepción.

[...] cuando los agricultores se han sentido solos, han rechazado ofertas de crédito y otras oportunidades porque no se sienten capaces y sienten el temor de no poder producir lo suficiente para pagar, y ese es un problema de sostenibilidad (Lalo, consultor privado).

A este problema se agrega, desde la percepción de los actores del ámbito privado, las débiles capacidades de quienes lideran las asociaciones, la gran cantidad de adultos mayores participantes, la poca continuidad de los proyectos de apoyo a las asociaciones (duran como máximo dos años) y la desarticulación entre los esfuerzos desplegados para consolidar las propuestas que ya se encuentran en proceso de formalización (elemento con el que coinciden los actores del sector público).

En lo que se refiere a la segunda posición, los actores del ámbito público identificaron la falta de un enfoque empresarial en las asociaciones. En este sentido, categorizan la asociación como un primer paso para consolidarse como una empresa o cooperativa que amplíe las oportunidades productivas y de inserción en el mercado laboral. Sin embargo, si bien consideran que las asociaciones deben seguir incrementando su cooperación hasta consolidarse como una empresa, identifican que hay una seria falta de participación entre los asociados y desconfianza hacia ellos por otras instituciones. 
[...] los empresarios no creen en las asociaciones porque muchas veces han participado en las asociaciones y lo que ha pasado es que los dirigentes han desaparecido con los fondos, con los libros y ha habido broncas tremendas (Rosa, coordinadora de una entidad estatal en Moquegua).

Ello coincide con otros entrevistados, quienes identifican que cada asociado de estas organizaciones "[...] tira para su lado», en referencia a que únicamente se preocupan por cómo ellos mismos van a verse beneficiados, sin considerar el interés por la asociación a la que pertenecen. Esta falta de compromiso y poca participación no solo la identifican entre las propias asociaciones, sino también en los potenciales compradores; al respecto, se señala que:

[...] a la hora de que quieren negociar sus producciones, como asociación, quedan a un precio y con una empresa, $y$, de repente, viene otra empresa y les dice «te voy a pagar 5 céntimos más». Pues el productor deja tirado su compromiso de acá y deja se va con el otro que le pagó 5 más [...] Existe una falta de compromiso, de seriedad, de cumplimiento por los productores y creo que eso sucede porque eso lo trabajan como una asociación, no como una empresa (Carmen, directora de una entidad estatal en Moquegua).

De forma adicional, los actores del ámbito académico, además de ahondar también en las debilidades de compromiso y formalización en las asociaciones, resaltan el vínculo social entre los pequeños productores. Al respecto, identifican que no existe una visión conjunta en las asociaciones que sea planificada, que les permita consolidar de forma sostenible su propuesta para el mercado. La falta de confianza y el temor a ser engańados son dos de los elementos que más alejan al pequeño productor para buscar asociarse.

En ese sentido, debido al bajo capital social identificado, así como la ausencia de una mirada de gestión estratégica empresarial, la asociatividad en Moquegua se encuentra fuertemente comprometida. Los pequeños productores no identifican posibles incentivos para trabajar de manera colectiva y, en caso de hacerlo, la sostenibilidad no está garantizada, toda vez que no disponen de una mirada de lago plazo sobre las ventajas de la asociación.

\section{Productividad y comercialización}

En lo que respecta a la productividad, todos los actores coincidieron en identificar a Moquegua como la región con ventajas comparativas para la agricultura: cuenta con buenas condiciones climáticas y suelos fértiles, además de no ser recurrentes las plagas ni enfermedades que puedan afectar las producciones. No obstante, identificaron diversos problemas relacionados con los procesos productivos que impiden incrementar la eficiencia en el cultivo y sacar el máximo provecho al proceso de producción. 
En primer lugar, los actores del sector público reconocieron como problema central la falta de infraestructura adecuada para optimizar los procesos de producción. Como bien explica una entrevistada, «en realidad en Moquegua no existen infraestructuras de este tipo. La única infraestructura importante que se puede considerar en Moquegua es un packing de palta de la que sale de exportación» (Carmen, directora de una organización del sector público). Sumado a ello, la falta de capacitación en el uso e implementación de nuevas tecnologías limita considerablemente su adopción para la optimización de procesos productivos.

En segundo lugar, actores del ámbito privado identificaron el uso del agua y las técnicas de riego como otro elemento a mejorar asociado a la productividad. Si bien se han hecho inversiones considerables en infraestructura de riego, actualmente esta no se utiliza, principalmente por un factor «cultural» asociado al uso de nuevas tecnologías. En contraposición a ello, se utilizan aguas recicladas que, acorde a uno de los entrevistados,

[...] en base a los últimos estudios realizados, está demostrado que el uso de aguas recicladas afecta a la productividad... (Daniel, encargado de monitoreo ambiental participativo en una empresa privada en Moquegua).

Por otro lado, los actores identifican la necesidad de un mapeo de suelos y la contratación de asesores productivos que capaciten a los técnicos de las asociaciones.

Una cosa fundamental en la asociatividad son los técnicos como los ingenieros, economistas, pero sobre todo los técnicos del mando medio, aquellos que hacen el trabajo productivo, los que te dicen cómo se poda la vid, qué tipo de suelo necesita el palto (Lalo, consultor privado en una empresa de Moquegua).

En este aspecto coinciden los actores académicos, quienes identifican que el incremento de capacidades, específicamente en la gestión empresarial, es aquello que prima para profesionalizar la actividad agrícola; de modo que pueda concebirse un negocio e incorporar un planeamiento estratégico. Adicionalmente, un factor importante que identifican es que menos del $10 \%$ de agricultores reinvierte parte de sus ingresos, siendo este un elemento crucial para que la producción no solo se mantenga, sino también crezca. Es necesaria una inversión constante que vaya incrementándose en el tiempo, no solo para mejorar la producción, sino también para mantener el suelo y demás recursos en óptimas condiciones para su uso.

Por otro lado, en lo que respecta a comercialización, el pequeño productor de la región se especializa en la venta al mercado local, pocas veces estandarizada y al mejor postor. Tres elementos que resultan, desde la perspectiva de los actores entrevistados, contrarios al ideal que se busca entre las asociaciones. Primero, consideran que debería estandarizarse los productos a ser vendidos para, a partir de ello, fidelizar compradores que, como consecuencia, les permitan ampliar su red de ventas y 
expandir su comercio a no solo mercados locales, sino regionales e internacionales. El reducido tamańo de sus unidades no permite que tengan productos suficientes para la demanda de otros mercados, al respecto, una entrevistada señala lo siguiente:

En otras regiones, sí puedes encontrar que un productor tiene 20-30 hectáreas, empresas que tiene 500 hectáreas para arriba. Aquí, el promedio de área es de una hectárea, media hectárea. [...] Entonces la única manera para que estos pequeñitos puedan salir competitivamente al mercado es haciendo una marca colectiva (Carmen, directora de una institución del Estado).

En particular, la totalidad de actores coincide en la necesidad de fomentar una marca colectiva que genere identidad a la calidad de los productos que se exportan, como una potencial solución que permita elevar los estándares de calidad y aumentar la producción global orientada a mercados específicos. Al respecto, son múltiples los casos de productores que, debido a que intentan acceder a otros mercados de forma individual, se han visto afectados por estándares requeridos a los cuales, individualmente, no les es posible alcanzar.

Hemos participado en ruedas de negocios en las que nuestros productores se han encontrado con un portazo en la cara. Porque a la hora que han querido salir al mercado, los compradores que tenía muy buenos pedidos les han dicho: «Bueno, te compro, pero ¿¿dónde es tu packing? ¿Dónde está tu registro sanitario? ¿Y cuál es tu planta de procesos?». «No, no tengo», «Ya, muchas gracias, cuando tengas me buscas». Excelentes compradores de Brasil, de Bolivia, de Chile, de Ecuador, de España, en fin (Carmen, directora de una institución del Estado en Moquegua).

Este tema se vincula directamente con la gran dificultad identificada que tienen los productores para participar, de forma completa, en toda la cadena productiva vinculada a la generación de productos de calidad internacional. Son varias las instancias de la cadena productiva a las que un pequeño productor, de forma independiente, es sumamente complicado que pueda acceder. Algunos entrevistados resaltan que

[...] en Moquegua no tenemos los que conforman toda la cadena de valor. Por ejemplo, necesitamos trasladar la palta de aquí a Santiago. Necesitamos un termoking con atmósfera controlada, en Moquegua no tenemos proveedor de eso. Los pisqueros necesitan las botellas, deben ir hasta lima para comprar las botellas. Y normalmente cada uno las compra por su lado. Son pocas veces que he visto que han hecho compras conjuntas. Para la cosecha de uva, por ejemplo. La uva de mesa, que es muy especializada. No tenemos el personal especializado, están trayendo la gente desde Ica. Además, otra cosa, que aquí el costo de mano de obra es carísimo. 70 soles cuestan un jornal más el almuerzo. O sea, está hablando de 76-77 soles aproximadamente ¿̨no? Entonces a la hora que tú quieres armar toda la cadena, es imposible (Carmen, directora de una institución del Estado en Moquegua). 
Los actores privados coinciden en la identificación de estas dificultades y precisan que, si bien es posible acceder a ciertos momentos de la cadena productiva, lo más urgente es la estandarización de los productos a partir de los requisitos que exige el mercado internacional para la venta. Este es un proceso complicado y demanda tiempo, pero como consecuencia de no hacerlo, la mayor cantidad de venta actual de los productos es a intermediarios que limitan la posibilidad de venta de sus productos a mayores precios. Es decir, la poca formalización de los productores, sumada al limitado acceso que tienen a varias etapas de la cadena productiva, restringe sus capacidades de acceso a nuevos mercados. Como menciona el mismo entrevistado, Taison:

[...] que siempre o la mayoría de veces lo hacen por terceros, no directamente con el mercado de destino con las personas que están comprando el producto. Entonces yo creo que ese es el problema que podrían tener. Encontrar un mercado adecuado para la cantidad de producción que puedan tener (Taison, coordinador de una institución educativa en Moquegua).

Los procesos que se identifican son necesarios, ya que funcionan como mecanismos para reducir las condiciones de desigualdad entre los productores y los compradores intermedios, mejorando sus oportunidades al momento de concretar una venta. La prestación de asistencia y realización de actividades, por ejemplo, por empresas de la zona, instituciones públicas y fondos de fomento al desarrollo sostenible de nuevos proyectos, son mecanismos que contribuyen a justamente reducir tales condiciones y mejorar las oportunidades para acceder a otros mercados por parte de los pequeños productores.

\section{El PEQUEŃO AGRICULTOR Y LA ASOCIATIVIDAD}

La vista a la posición de los agentes públicos, privados y académicos nos da una perspectiva del entorno que da soporte a las asociaciones; luego de ver la parte macro se pasará a presentar las asociaciones como tal y su quehacer. Se plantea que la asociatividad, reconocida como una opción óptima para los pequeños productores, puede tener un impacto definitivo en sus oportunidades productivas, en tanto permite el acceso a redes y mercados regionales e internacionales, tener estabilidad, compartir costos de producción y recibir invitaciones a capacitaciones. Para comprender la influencia tangible de la asociatividad, en el acceso a las oportunidades productivas de los pequeños productores, se analizaron cuatro asociaciones de la región Moquegua, las cuales reúnen en conjunto un total de cien pequeños productores. En la siguiente tabla se detalla información general de cada asociación. 
Tabla 2. Información general de cada asociación a 2018

\begin{tabular}{lccc}
\hline Nombre & $\begin{array}{c}\text { Asociados/ } \\
\text { entrevistados }\end{array}$ & $\begin{array}{c}\text { Ańos } \\
\text { activos }\end{array}$ & Producto \\
\hline Asociación Pioneros de San Cristóbal & $29 / 22$ & 4 & Tuna \\
\hline $\begin{array}{l}\text { Asociación de Productores Agrícola y Exportadores de } \\
\text { Moquegua - APAEXMO }\end{array}$ & $19 / 16$ & 4 & Palta Hass \\
\hline $\begin{array}{l}\text { Asociación de Vitivinicultores de Moquegua - AVIMO } \\
\text { Asociación de productores de Cuy - ASPROCUY }\end{array}$ & $30 / 11$ & 15 & $\begin{array}{c}\text { Uva Red } \\
\text { Globe }\end{array}$ \\
\hline
\end{tabular}

Para vislumbrar la relación de los pequeños productores con la asociatividad, y cómo esta influye sobre sus oportunidades productivas, se profundizó en la relación del pequeño productor con la asociación a la que pertenece, desde el punto de vista de los medios de vida establecido por la DFID. Entenderemos esta relación en función del acceso a los recursos o capitales (humano, social, natural, físico y financiero) a los que tienen acceso; de otro lado, se busca conocer cómo las asociaciones se desempeñan desde un punto de vista organizacional.

Asociación Pioneros de San Cristóbal. Esta la única de las asociaciones que se encuentra alejada geográficamente (distrito de San Cristóbal) de la capital de Moquegua; la mayoría de sus integrantes son mujeres (una característica particular que la diferencia de las otras asociaciones), y la media en educación es primaria completa o secundaria incompleta. La venta del producto es principalmente local; dependen de intermediarios.

El capital natural es uno de los determinantes para el desarrollo de las pequeñas productoras; es decir, limita la producción y su crecimiento debido a que las áreas de cultivo se encuentran muy alejadas entre sí y del poblado, además de ser pequeñas en extensión (entre 1/3 de hectárea a una). La distancia y el tamaño limitan la atención que se puede dar a la parcela, el traslado del producto y la cantidad del producto que se puede cultivar para venta, en espacial el traslado se convierte en un obstáculo para el trabajo de la asociación.

[...] del cultivo de la tuna, lo que más complica [...] es el transporte, no hay vías. Necesitamos apoyo del gobierno, en el agua, eso necesitamos, nos faltan muchas cosas [...] (asociado $\mathrm{N}^{\circ}$ 1, Asociación San Cristóbal).

Otra necesidad que se enmarca en el capital natural es la gestión del agua; al ser este un recurso clave para el cultivo, resulta necesario contar con el conocimiento para implementar otros métodos de riego y dejar los métodos no tecnificados 
usados actualmente para el cultivo y cosecha de la tuna. Ambos elementos resultan determinantes, desde los aportes de Paredes y Fort (2018), en lo que respecta a la asociatividad. A esto se suman el capital físico o de infraestructura, los medios de comunicación e infraestructura vial adecuada para mantener a las pequeñas productoras conectadas entre ellas y con su entorno. Actualmente, por la distancia, el acceso a internet o telefonía es restringido. Además de los dos capitales mencionados, los productores individuales no tienen el acceso libre a créditos y préstamos (el principal factor es la pequeña cantidad de terreno individual del que disponen).

Con la creación de la asociación, se implementaron trabajos de faena entre los integrantes para ayudar en la preparación, recolección y manejo de plagas, lo cual, además de impulsar el desarrollo de cada pequeña productora, genera compañerismo y camaradería estableciendo una red de soporte que beneficia a los asociados, puesto que comparten una meta común. La participación de los integrantes ayuda a lidiar con las limitaciones del capital natural y el físico, además de potenciar el capital social (se transciende el campo de la familia y amigos los cuales pueden o no compartir el conocimiento del cultivo y cosecha de la tuna). El capital social para esta asociación se convierte en un factor clave para hacer frente a los determinantes de los que no dispone, permitiendo su continuidad, fortaleciendo los lazos y la confianza entre las asociadas, además de impulsar su organización, una línea que mantiene una cierta sostenibilidad a diferencia de otras asociaciones.

Un capital importante para las asociadas, y al que tienen acceso por pertenecer a la asociación, es el humano. Nos referimos al desarrollo de las habilidades y capacidades por medio de la asistencia a capacitaciones ofrecidas, ya sea por el estado como el municipio o por una entidad privada como el Fondo Quellaveco. El desarrollo de las asociadas depende mucho de las capacitaciones a las que pueden asistir. Para el caso de estudio, y como es señalado por los agentes en el acápite anterior, las capacitaciones preparadas por las entidades públicas (por ejemplo, el Ministerio de la Producción, la municipalidad) y privadas (como el Fondo Quellaveco) son difundidas entre los integrantes de las asociaciones y se centran en su mayoría, en métodos de cultivo, tratamiento y cosecha. Asimismo, es la propia asociatividad y las cadenas productivas las que facilitan, efectivamente, el acceso a capacitación y apoyo de actores externos, demostrando alinearse con el aporte de Paredes y Fort (2018). Sin embargo, quedan temas considerados clave por los asociados y asociadas que no suelen ser ofrecidos en las capacitaciones:

[...] lo que más a mí me gustaría aprender, lo que es no, conseguir variedades que nos traigan. Suelen decir que hay bastantes variedades de tunas, pero aquí solo hay cuatro. [...] Nos gustaría tenerlas, poder cultivar, es importante conocer la variedad. Otro conocimiento necesario es como marketear, para poder vender [...] es necesario poder incorporarlo a todo el poblado de San Cristóbal (asociado $\mathrm{N}^{\circ}$ 1, Asociación San Cristóbal). 
Es clave, en este caso, resaltar la fortaleza de la organización que se llegó a crear. A diferencia de las demás asociaciones, Pioneros de San Cristóbal tiene un reglamento formal que reconoce a los integrantes activos; asimismo, existen mecanismos de sanción para los que no dan el aporte. El alto compromiso de los integrantes activos cultivado por el capital social, se evidencia en el nivel de transparencia que tiene la organización y que permite la consolidación del grupo. La asociación cuenta con un organigrama y sus integrantes procuran separar el trabajo mediante el establecimiento de comisiones, tienen reuniones periódicas donde conversan sobre los quehaceres de la asociación, además de reunir un pequeño fondo para emergencias, entre otros.

Si bien hay aspectos que fortalecer, por ejemplo, respecto de los integrantes y los determinantes en materia de acceso al riego, la mayoría son pequeñas productoras que no muestran interés por acceder a puestos de liderazgo al interior de la asociación (al tener menor nivel educativo, no desean ocupar este tipo de cargos), lo cual impacta en la Junta Directiva y el tiempo que esta se mantiene. Ahora liderada por un varón, esta va extendiendo sus funciones, centrando las acciones de la asociación en la figura de una persona y no de la directiva, aspecto que a largo plazo puede detener el crecimiento de la asociación. Cabe precisar que los inconvenientes presentados referentes a la gestión del agua no representan el principal impedimento para detener la actividad agropecuaria en la región, toda vez que solo el 5,3\% de productores que señalaron haber dejado de participar de la actividad agrícola lo hicieron por falta de agua, según la Encuesta Nacional Agrícola 2018.

APAEXMO. Es la única de las asociaciones que tiene venta para exportación. La mayoría de integrantes son varones y mayores de cincuenta ańos. Asimismo, a diferencia de la asociación previamente analizada (Asociación Pioneros de San Cristóbal), tienen un nivel educativo en conjunto de: superior-universitario (mayoría - alto capital humano); no obstante, dicha composición no resulta similar a escala departamental, pues solo el 5,2\% de los productores cuenta con un nivel educativo superior universitario completo y $6,9 \%$ superior no universitario completo. Una peculiaridad de esta asociación es que nace de otra asociación llamada Siglo 21, es decir, sus integrantes ya tienen experiencia con otras asociaciones.

Con respecto al capital natural, las tierras o espacio individual del que disponen para cultivo es mucho mayor que el de la Asociación Pioneros: alrededor de 3 hectáreas o 1, lo cual permite que se enfoquen en su principal problema, el acceso al agua. El cultivo de la palta Hass, al requerir grandes cantidades de agua, exige una gestión eficiente de este recurso. Este requerimiento se constituye en una de las razones que dio lugar a la creación de la asociación y, por tanto, uno de sus objetivos principales es que todos los integrantes puedan acceder al agua con el fin de obtener la cantidad necesaria para el cultivo de la palta y poder evitar el robo o informalidad en el uso del recurso. En ese sentido, más que ser un determinante 
para la asociatividad, la falta de acceso al agua ha sido el elemento que ha impulsado esta organización y su participación en las cadenas de valor, poniendo de debate los determinantes definidos por Paredes y Fort (2018).

Por otro lado, sobre el capital físico, el transporte del producto no genera un gran problema: al pertenecer a la asociación, ahora los integrantes recurren a alianzas (pueden juntarse o juntos reunir el capital para contratar movilidad) para llevar a cabo el traslado. Sí se plantea la necesidad de tener apoyo de las instituciones públicas o privadas respecto de infraestructura de riego que beneficie a sus cultivos y vías accesibles. Por otro lado, a diferencia de otras asociaciones, APAEXMO tiene tres motores estacionarios para fumigar que se encuentra a disposición de todos los asociados.

Si bien los asociados pueden reunir el capital necesario para cubrir algunas necesidades que puedan presentarse (compras conjuntas, de fertilizante o contrata de movilidad), la asociación no tiene un fondo de emergencia que permita establecer una planificación a largo plazo. Debido a esto, como organización no tienen acceso a crédito o préstamos; sin embargo, los asociados sí acceden a créditos personales que pueden pedir como garantía el terreno de cultivo. A diferencia, por ejemplo, de Pioneros, el capital financiero individual puede impulsar el desarrollo del pequeño productor. Para el caso de APAEXMO, este capital no es uno de los principales objetivos que impulsó el ingreso de los pequeños productores a la asociación. La visión utilitaria que marca a la pertenencia a la asociación no es financiera, sino centrada en la gestión del capital natural y social.

[...] no tenemos un fondo común, cuando se necesita hacemos un aporte, de repente estoy equivocado, pero a veces será por la experiencia, pero no me gusta tener dinero para manejar porque a veces eso como que corrompe, $[\ldots]$ de repente habiendo plata este se gasta, [...] solo se pide las cuotas cuando se requiere para algo [...] hacemos compras conjuntas o movilidad para traer a la ingeniera (asociado $\mathrm{N}^{\circ} 1$, Asociación APAEXMO).

Los capitales natural y social, son los que impulsan y desarrollan al asociado; por un lado, para el caso de APAEXMO la gestión del agua, uno de los recursos más importantes, es clave para su desarrollo y la gestión en grupo favorece a todos los asociados. Por otro, en mayor o menor medida, la existencia del apoyo de los otros integrantes (que se mueven en el mismo sector y tienen el cultivo del mismo producto) genera un ambiente de apoyo y comprensión, lo que impulsa el desarrollo del asociado.

[...] hay agua, el problema es la gestión del agua a nivel de pasto grande si hubiera gestión habría agua, esta debe ser a nivel regional, de cuenca, y así alcanzaría, pero no. El agua se desperdicia, cualquiera va al canal y se puede instalar el agua, quien 
dice algo sobre eso, nadie [...] reclamamos, pero nos pasean, hacemos marchas, pero nada [...] (asociado $\mathrm{N}^{\circ} 2$, Asociación APAEXMO).

El capital humano también toma importancia, pues al ser asociado se tiene acceso a las capacitaciones que ofrecen las demás entidades, lo que permite mejorar las habilidades y capacidades con respecto al cultivo y un poco a la gestión. Esto se aplica a todas las asociaciones. En efecto, se cumpla la reducción de los costos de transacción referentes al acceso a información de mercados, capacitaciones y apoyo de los actores del entorno, tal y como desarrollan Paredes y Fort (2018).

A diferencia de Pioneros, y siguiendo la línea de las demás asociaciones, desde un punto de vista organizacional, APAEXMO es una organización pequeña, no tiene una planificación que le permita crecer de manera sostenida a largo del tiempo, y si bien se reconoce el beneficio de formar parte de una asociación solo se concentran en acciones a corto plazo. No cuenta con una distribución clara de funciones o comisiones como Pioneros; los asociados no están sujetos a cuotas fijas o reuniones periódicas, se reúnen y aportan cuando surge la necesidad concreta de grupo (por ejemplo, la gestión del agua o compra de insumos). Esto impide que la asociación como tal pueda no solo aplicar para el acceso a préstamos o crédito u otros requisitos necesarios para impulsar el ingreso de la asociación a mercados más grandes, sino además planificar e implementar los planes que puedan necesitar. Asimismo, al no tener reuniones periódicas, la coordinación entre los integrantes para cosecha, traslado y venta (que no es directa sino por medio de intermediarios) es deficiente y toma tiempo (el trabajo en equipo puede verse comprometido), lo que impulsa a los integrantes a buscar ventas individuales o unirse a otras redes si aparece la oportunidad, a pesar de tener un contrato que la asociación mantiene con la Empresa Camet Trading. No obstante, cabe resaltar que se evidencian impactos en la productividad esperados, acorde a los aportes de Minot y Sawyer (2014). Los juegos de poder aún vigentes en la asociación se presentan como un elemento que pone en riesgo la asociatividad, coincidiendo con Paredes y Fort (2018).

AVIMO. Es la asociación más antigua del grupo; con más integrantes varones, cuyo promedio de edad ronda por los 50 a 60 años. La mayoría tiene una educación superior inconclusa, lo cual se evidencia en la fortaleza de su capital humano: en Moquegua, 7,9\% de los productores registran contar con educación superior incompleta, sea universitaria o no universitaria, según la Encuesta Nacional Agropecuaria 2018.

Al igual que APAEXMO, los integrantes de AVIMO tienen a su disposición tierras de cultivo cercanas a la ciudad, lo que les permite gestionar la producción de uva Red Globe y ha funcionado como un determinante para su asociación. Los productores vienen trabajando con el fin de poder tener un producto estandarizado, para lo cual el acceso al agua es importante, mas no determinante. Al respecto, se 
observa que el capital natural es un gran impulso para que los pequeños productores se asocien, fomentando así una mejor gestión del acceso al agua para el cultivo. En particular, se observa que el capital social juega un papel relevante, pues se ha generado una conciencia de grupo que permite compartir una misma meta, como es incrementar la cantidad y calidad del producto para la venta, teniendo a su vez un impacto sobre la productividad y los mecanismos que contribuyen a ello. A pesar lo señalado, esta cohesión es frágil y la asociación no está libre de problemas de confianza entre los asociados.

Por otro lado, en lo referente al capital físico, la asociación no tiene un medio de transporte que reúna toda la producción de los asociados. Como consecuencia, estos se ven obligados a procurar su propio transporte, el cual puede demorar o no reunir las condiciones que permitan mantener / proteger la integridad del producto. Se considera este como una limitante para mejorar la comercialización.

[...] un sistema de packing nos abriría las puertas a otros mercados, ya que ese es nuestro principal problema [...] tuvimos un problema con una exportadora en el 2014, en la etapa final, se cae la venta por el transporte hacia el packing más cercano, en Arequipa, el costo era asumido por el productor y tampoco tenían las javas necesarias [...] (asociado $\mathrm{N}^{\circ} 1$, Asociación AVIMO).

Actualmente se cuenta con un pequeño fondo que solo se dirige a capacitaciones y asesorías, dejando de lado necesidades más apremiantes, como la compra de tecnologías; por ejemplo, la adquisición de un sistema de empaquetado que permite mantener la fruta. Este se constituye en el capital financiero de la asociación. Se espera que la asociación pueda crear un fondo común que beneficie a todos. Actualmente los pequeños productores pueden acceder a crédito personal.

Uno de los puntos que valoran los integrantes es la participación en las capacitaciones que se ofrece a las asociaciones y les dan acceso a nuevos métodos de cultivo o cosecha que permitirán alcanzar la meta de los asociados.

La asociación como organización, a pesar de ser una de las más antiguas, aún es frágil, lo que se evidencia en la fragmentada cohesión de sus integrantes evidente en dos puntos: (i) existencia de una práctica individual alta (los asociados no se centran en la venta como asociación sino además están dispuestos a elegir una venta individual de presentarse la oportunidad), debilidades que nos les permiten prescindir del intermediario y tener un acceso libre o fluido a la cadena productiva, y (ii) como consecuencia no cuentan con una manera objetiva o real de poder constatar el alcance final de su producto, y sin un acceso al comprador final no tienen los medios para percibir los cambios en el mercado (por ejemplo el cambio del consumo de uvas con pepas a sin pepas, mencionado por uno de los agentes clave). Esto deja al capital natural — debido al interés en el acceso y gestión del aguacomo el principal agente que cohesiona a la asociación. 
Cabe resaltar que esta es la primera asociación que menciona la participación en proyectos para la mejora de su producción, convocados por programas estatales como el Programa Nacional de Innovación Agraria (PNIA), entre otros. Se percibe como un beneficio acceder a estos fondos; sin embargo, es necesario señalar que el objetivo de estos fondos es dar un impulso final o consolidar un desarrollo (hasta tres ańos), no dar un respaldo a largo plazo. Sin perjuicio de ello, el acceso a dichos proyectos se ha concretado gracias a la concentración de los capitales descritos, y las características de tipo etarias o educativas no se constituyeron como restricciones de entrada para la asociación.

ASPROCUY. Al igual que San Cristóbal, dispone de integrantes que tienen una educación escolar completa o incompleta. Esta asociación sigue la línea de las demás organizaciones y sus integrantes tienen un rango de edad mayor $(50+)$.

Con respecto a las oportunidades productivas a las que puede acceder el pequeño productor (en este caso se refiere a crianza de cuyes), el capital físico tiene preminencia sobre el capital natural, pero no es el determinante que mantiene a la asociación. La construcción de un galpón donde se dé la crianza adecuada de los cuyes influye sobre la cantidad que pueden llegar a reunir los pequeños productores; sin embargo, no todos los productores cuentan con la misma cantidad de galpones ni estos tienen la misma capacidad. Asimismo, los asociados, para la atención de los cuyes, no recurren a la familia sino a personal contratado.

Para llegar a las cantidades necesarias para venta, puede haber la alianza entre los asociados que tiene menor producción u optarse por la venta individual, lo cual evidencia lo efímero del capital social para este caso. Aquí, esta asociación, a diferencia de las anteriores, tiene contacto directo con los compradores (estos pueden ser los dueños de restaurantes o del mercado).

[...] la mayoría [de los asociados] no quieren criar [...] ellos tienen trabajo seguro, nunca pusieron bien la fuerza de trabajo, a los cuyes [...] ahora no estamos emprendiendo o intentando hacer $[\ldots]$ hay mercados, pero no tenemos producción, ni con los catorce que somos (asociado $\mathrm{N}^{\circ} 1$, Asociación ASPROCUY).

$\mathrm{Al}$ igual que en todas las asociaciones, se valora la posibilidad de participar en capacitaciones que les permita desarrollar su capital humano y a las que tienen acceso por formar parte de una asociación. Este desarrollo contrasta con la diferencia que existe entre los integrantes de la asociación que cuentan con diferentes capitales físico, financiero y social, lo que les permite comercializar de manera individual, dado que es el capital humano (acceso a conocimientos técnicos, productivos y de comercialización) el que abre la posibilidad para insertarse en el mercado y les permite obtener un nivel de equilibrio en sus relaciones contractuales a pesar de las diferencias en los otros capitales. 
Como organización, ASPROCUY tiene una estructura que categoriza a los integrantes según su participación (activo/no activo). Dentro de la categoría de «no activo» se encuentra la mayoría de la dirigencia de la asociación. Al no tener una dirigencia activa que responda a las necesidades de los pequeńos productores (no se registran reuniones o coordinación permanente entre los asociados), como consecuencia, se tienen integrantes no comprometidos que comercializan de manera individual y en los últimos años la asociación ha ido perdiendo integrantes. Este elemento no se ha presentado como determinante para la asociatividad, ni tampoco aparecen ninguna restricción de entrada mencionada en el acápite 2 , pero se evidencia como resultado del trabajo de campo y que afecta finalmente la sostenibilidad de la asociatividad. En efecto, se atribuye la subsistencia de la asociación a la influencia de factores externos como la atención de organizaciones estatales y privadas, también de las ONG, o a la participación en concursos para emprendedores. En ese sentido, se puede observar que las cadenas de valor adoptadas, así como los costos de transacción asumidos como parte del proceso de organización, son los elementos que permiten la permanencia de la asociación.

Las oportunidades productivas desde la perspectiva de los asociados, de acuerdo con lo estudiado en campo, muestran que el principal incentivo / interés que reúne a los productores para formar una organización es el capital natural. El capital natural, en la gestión del agua, da paso a la creación de la asociación, que posteriormente encuentra en los capitales social, físico y humano, incentivos para mantener unidos a los asociados. Los asociados reconocen la importancia de reunir la producción de varios pequeńos productores para poder aumentar la cantidad disponible para venta; por lo tanto, se valora a la asociación no solo por su capacidad de convocatoria sino además por el acceso al apoyo o respaldo que puedan ofrecer los pequeños productores entre ellos (Pioneros, APAEXMO y AVIMO).

Con respecto al capital físico, se reconoce la deficiencia que existe en los bienes disponibles para transporte como la infraestructura vial (vías de acceso) y de acceso a las comunicaciones, responsabilidad que recae en la acción pública (Pioneros), y también los bienes que la asociación puede adquirir sumando como interés común en algunos casos la posesión de un medio de transporte (camión para Pioneros) y equipo especializado para el producto (sistema de empaque - AVIMO). A lo señalado se suma la valoración de las capacitaciones (todas las asociaciones), que suman al fortalecimiento y empoderamiento del capital humano de cada pequeño productor, al poder asistir a las capacitaciones que dan las entidades tanto públicas como privadas. Los pequeños productores plantean la necesidad de no solo poder fortalecer su conocimiento sobre técnicas de cultivo y cosecha, sino, además, sobre gestión de pequeñas organizaciones, procesos y métodos para insertarse de una manera formal en el mercado local, nacional e internacional (conocer el ciclo de la cadena productiva). 
Para el caso de ASPROCUY, el capital financiero es más bien el que impulsa a la asociación; sin embargo, en la práctica no funciona de forma organizada, pues los asociados no se sienten en condiciones iguales para aportar al desarrollo del capital físico y financiero, que les permitiría aprovechar oportunidades de mercado de manera colectiva, primando la salida individual.

Además del desarrollo o consolidación de los capitales relacionados con las oportunidades productivas evidente en el análisis de cada asociación, es relevante recalcar el aspecto organizacional: la creación y consolidación de una asociación, que tiende a tener características clave como división de labores, responsabilidades, puestos y procesos, además de otras particularidades que forman su identidad, como el liderazgo, interés común, alto compromiso, confianza, cohesión interna, capacidad organizativa, responsabilidad, funciones claras, etcétera. Estos son los componentes del sistema que soporta a la organización.

Para los casos estudiados, las asociaciones como organización tienen un largo camino por recorrer; Pioneros tiene un gran avance en la implementación de las comisiones para el desarrollo de la asociación, y el alto compromiso de las asociadas (capital social); sin embargo, su Junta Directiva no se renueva por falta de voluntad de las asociadas para tomar el liderazgo. APAEXMO tiene asociados comprometidos bajo el capital natural (acceso al agua) que los reúne bajo una sola meta; a pesar de ello se constituye en una organización con coordinaciones selectivas de corto plazo. Por otro lado, AVIMO también se conforma por pequeños productores unidos por el capital natural; sin embargo, respecto de la comercialización, no cuenta con integrantes comprometidos de manera sostenible con la asociación. Para finalizar, ASPROCUY presenta un grave problema de liderazgo de la Junta Directiva, la cual no es activa, unidos precariamente por el acceso al capital físico y natural. Actualmente es la asociación más frágil de las cuatro estudiadas.

La permanencia de las asociaciones de pequeños productores es influenciada no solo por la participación de los agentes públicos y privados que tienen un rol de soporte y guía, sino además por la misma predisposición de los pequeños productores y el manejo de los capitales y oportunidades productivas. Los determinantes descritos en el acápite 2 cumplen un rol fundamental, con excepción del acceso al agua, que en lugar de ser un elemento necesario, es un componente estructural para la asociación en los casos estudiados. A partir de lo señalado, se puede afirmar que la asociatividad —como mecanismo colectivo de cooperación-tiene efectos relativamente positivos en la producción. Sin embargo, existen otros factores que debieran tomarse en cuenta para que efectivamente se generen y aprovechen oportunidades productivas. Uno de los factores que podría explicar el éxito de una asociación estaría relacionado entonces con el liderazgo, la gestión y modelo organizacional; si bien las asociaciones estudiadas presentan ciertas fortalezas al respecto, todavía se perciben debilidades organizacionales importantes. 


\section{CONCLUSIONES SOBRE LA ASOCIATIVIDAD COMO IMPULSORA DE LAS OPORTUNIDADES PRODUCTIVAS}

Si bien la asociatividad, tal como ha sido presentada desde la visión de los actores públicos, privados y pequeños productores entrevistados, puede tener una imagen positiva como opción para incrementar la producción y acceso al mercado, se ha encontrado que existen varios desafíos críticos para ponerla en marcha y percibirla como una real opción de fortalecimiento de las unidades productivas.

Un primer factor que motiva de manera estructural a la asociatividad es el capital natural, en nuestro caso el recurso agua. Paredes y Fort (2018) describen que el acceso al agua es un determinante para la asociación, se ha observado durante el trabajo de campo que al menos dos asociaciones (APAEXMO y AVIMO) sustentan el motivo de su asociación en justamente la gestión y acceso a dicho recurso. Sin esta voluntad de cooperar, el costo para producir y comercializar sería alto, pues dependen de este recurso para subsistir y realizar sus ventas. Sin embargo, los demás capitales — financiero, físico, humano y social— van a negociarse en función del control que cada unidad productiva tenga sobre estos. La inestabilidad de la asociatividad tiene que ver mucho con la desigualdad en el control de estos capitales. Aquellos miembros que tengan mayor control sobre ellos podrán negociar sus intereses en el mercado sin necesidad de depender de la voluntad del colectivo. Cabe resaltar que las oportunidades productivas obtenidas como resultado de la asociación (tales como las capacitaciones, venta colectiva, trabajo con otros actores) también se presentan como elementos clave en la permanencia de las asociaciones.

Un segundo factor que promueve el trabajo colectivo es la tradición social y cultural de las unidades productivas en territorios relativamente distantes de las ciudades y, por lo tanto, de mercados consolidados (Pioneros de San Cristóbal). En ese sentido, las costumbres y valores conforman la base para construir una cultura de confianza que fortalezca la reciprocidad, generando así el capital social necesario para desarrollar la asociatividad.

En tercer lugar, en aquellas unidades productivas en las cuales los capitales y recursos controlados son muy desiguales (ASPROCUY), la posibilidad de asociarse se hace más compleja y difícil, y por lo tanto, la voluntad de cooperar y asociarse dependerá en mayor medida de oportunidades concretas que el mercado ofrezca y el apoyo de entidades externas públicas o privadas que las impulse a trabajar de manera colectiva. En consecuencia, estas serán dependientes del entorno y no tanto de la voluntad propia para desarrollarse en esa perspectiva de manera sostenible; su volatilidad será la característica que las identifique.

En cuarto lugar, las fortalezas encontradas en las asociaciones (Pioneros de San Cristóbal) se centran en la tradición previamente mencionada o en el interés común 
que las reúne (APAEXMO y AVIMO), dejando de lado aspectos clave de desarrollo organizacional que impide el establecimiento de una cultura de cohesión en las asociaciones. El establecimiento de dicha cultura permite la consolidación de estos ámbitos de trabajo colectivo que puede, entre otras cosas, establecer procesos y renovar a sus integrantes; tomando en cuenta que la edad promedio de los asociados en todas las organizaciones está por encima de los cincuenta ańos.

A partir de estos casos podemos inferir que los factores que impulsan la asociatividad son estructurales (agua o tierra), culturales (valores y costumbres arraigados) y oportunidades del mercado apoyadas por agentes externos. La asociatividad en el mundo económico-productivo está basada principalmente en incentivos que generen réditos en favor de los productores que se asocian. No obstante, los determinantes para conformar una asociación desarrollados en el acápite 2 serán cambiantes para los cuatro casos observados y se mostrarán elementos como el acceso al agua, un motivo para la asociación antes que un impedimento para ella. Además, las cadenas de valor a las cuales se accedieron como asociación y la productividad obtenida generan incentivos adicionales para la asociación, pero también para el beneficio individual.

Para que esta se convierta realmente en una estrategia de sostenibilidad y desarrollo dependerá de dos aspectos clave: (i) el marco institucional en la cual se mueven las organizaciones de productores, y (ii) la capacidad de gestión que pongan en marcha los líderes para fortalecer un modelo organizacional que les permita aprovechar los recursos de manera efectiva y alcanzar resultados significativos.

En el caso de la región Moquegua, el contexto institucional público y privado está atomizado en sus competencias funcionales y objetivos particulares. Si bien existe un nivel de coordinación entre estas, la mirada de desarrollo territorial está aún en ciernes para apoyar y responder específicamente a los grupos de pequeños productores.

La articulación intersectorial todavía requiere políticas públicas regionales alineadas con las políticas de alcance nacional (por ejemplo, el plan de competitividad) que respondan con mayor rigor y fortalezcan los capitales con los cuales cuentan los pequeños productores. Por otro lado, las capacidades de gestión de dichas unidades productivas son muy disímiles y los liderazgos en mucho de los casos no se renuevan y mayoritariamente son asumidos por adultos mayores. En este último aspecto, los gobiernos provinciales y distritales pueden jugar un rol clave en el desarrollo económico local a través de concursos públicos que incentiven a los productores a asociarse para acceder a estos fondos. Este tipo de concursos podría generar cambios en la gestión y, por lo tanto, mayor efectividad en su desempeño productivo y aprovechamiento de oportunidades de mercado. 
Si bien Moquegua está dentro de las regiones con mayor impulso económico, las brechas sociales entre los actores todavía siguen siendo un reto a superar. Una mirada de mancomunidad, generación de clústers, acceso a tecnologías e información oportuna y de calidad e innovación social, podrían permitir un desarrollo acorde a las necesidades de estos sectores. Se requieren entonces consensos políticos expresados en planes y proyectos bien ensamblados y una arquitectura institucional que les dé viabilidad. Desde este marco, se incrementarían las posibilidades de incluirlos socioeconómicamente y ver objetivamente a los pequeños productores como una posibilidad que requiere inversión y no solo como un problema.

\section{REFERENCIAS}

Axelrod, R. M. (1986). La evolución de la cooperación: el dilema del prisionero y la teoría de juegos. Madrid: Alianza.

Axelrod, R. M. (2003). La complejidad de la cooperación: modelos de cooperación y colaboración basados en los agentes. México, D. F.: Fondo de Cultura Económica.

Azula Pastor, J. L. (2015). Alcances y limitaciones de una experiencia de asociatividad: Acciones productivas y comerciales de los pequeños agricultores algodoneros del valle de Pisco (trabajo no publicado). Lima: Pontificia Universidad Católica del Perú.

Banco Mundial (2017). Tomando Impulso en la agricultura peruana. Oportunidades para aumentar la productividad y mejorar la competitividad del sector. Lima: Grupo Banco Mundial.

Brasier, K., Goetz, S., Smith, L., Ames, M., Green, J., Kelsey, T., Rangarajan, A., Whitmer, W. (2007). Small farm clusters and pathways to rural community sustainabilitiy. Journals of Community Devolopment, 38(3), 7-22. https://doi. org/10.1080/15575330709489826

Cárdenas Grajales, G. I., Bedoya Patińo, C. G. \& Marín López, Y. (2015). Estrategias de adaptación y medios de vida de las familias integrantes de la Fundación Consejo Veredal (FCV), municipio de Calarcá, Quindío. Luna Azul, 41, 201-239 https:// doi.org/10.17151/luaz.2015.41.12

Centro de Exportaciones e Inversiones Nicaragua (2010). Asociatividad. Managua, Nicaragua.

De La Torre, L. M. \& Sandoval Peralta, C. (2004). La reciprocidad en el mundo andina. El caso del pueblo de Otavalo. Friedrich Ebert Stiftung y ABYA YALA.

De Remes, A. (2001) Elección racional, cultura y estructura: tres enfoques para el análisis político (Rational Choice, Culture and Structure: Three Approaches to Political Analysis). Revista Mexicana de Sociología, 63(1), 41-70. https://doi. org/10.2307/3541201

Del Valle, C. A. (2013). La actividad agraria con enfoque empresarial. Revista Nacional de Agricultura, 958, 16-24. 
Department for International Development - DFID (1999). Hojas orientativas sobre los medios de vida sostenibles. Recuperado de http://community.eldis.org/.59c21877/ SP-GS1.pdf

Devaux, A., Velasco C., López G., Bernet T., Ordinola M., Pico H., Thiele G., Horton, D. (2006). Acción colectiva para la innovación y el acceso de pequeños agricultores al mercado: la experiencia de Papa Andina. En Taller de investigación sobre acción colectiva y el acceso de pequeños agricultores al mercado. Cali, Colombia.

Diez, A. (2014). Cambios en la ruralidad y en las estrategias de vida en el mundo rural: una relectura de antiguas y nuevas definiciones. Perú: el problema agrario en debate (pp. 19-85). Lima: SEPIA XV.

Diez, A. (2006). Redes, organizaciones y movilidad económica en comunidades campesinas: el caso de Huayopampa. Debate Agrario, 40-41, 61-84.

Domínguez Orbegoso, A. R. \& Ulloa Mata, M. (2016). Innovación en las mypes de equipo eléctrico y de maquinaria y equipo de Los Olivos a partir de la asociatividad empresarial: estudio de casos múltiples (trabajo no publicado). Lima: Pontificia Universidad Católica del Perú, Lima.

Fairlie Reinoso, V. (2008). Asociaciones de pequeños productores y exportaciones de banano orgánico en el valle del Chira. Economía y Sociedad, 69, 31-39.

Ferrando Perea, A. (2015). Business Partnerships for Improving the Competitiveness of Small Farmers. Anales Cientificos, 76(1), 177-185. https://doi.org/10.21704/ ac.v76i1.779

Flores Galindo, A.. (1988). Los caballos de los conquistadores, otra vez: el otro sendero. En Tiempo de plagas (pp. 197-215). Lima: El Caballo Rojo.

Gobierno Regional de Moquegua (2013). Plan de Desarrollo Regional Concertado: Moquegua hacia el 2021. Moquegua: GRM. Recuperado de http://www.regionmoquegua.gob. pe/web13/file/files-ott/P-D-R-C\%20Moquegua\%20Hacia\%20el\%202021\%20 -\%20Ajustado\%20al\%20Plan\%20Bicentenario.pdf

Golte, J. (1980). La racionalidad de la organización andina. Lima: IEP.

Golte, J. (1992). Los problemas con las comunidades. Debate Agrario, 14, 17-22. Lima: CEPES.

Golte, J. \& Adams, N. (1990). Los caballos de Troya de los invasores: estrategias campesinas en la conquista de la gran Lima. Lima: IEP.

Golte, J. \& De la Cadena, M. (1983). La codeterminación de la organización social andina. Allpanchis, XIX(23), 7-34.

Gómez Núñez, N. (2016). Reciprocidad y cooperación en las economías latinoamericanas. Polis, 15(45), 63-85. https://doi.org/10.4067/S0718-65682016000300004

Hernández, R., Fernández, C. \& Baptista, P. (2014). Metodología de la investigación. Sexta edición. México: McGraw-Hill Interamericana.

Instituto Interamericano de Cooperación para la Agricultura (2004). Visiones y enfoques necesarios para desarrollar la Microempresa Asociativa Rural (M.A.R.) Alcances e importancia para los campesinos. Paradigma necesario para el éxito empresario. Módulo 1. Paraguay. 
Instituto Nacional de Estadística e Informática - INEI (2019). Informe Técnico "Comportamiento de los indicadores de mercado laboral a nivel nacional". Recuperado de https:// www.inei.gob.pe/media/MenuRecursivo/boletines/empleo-nacionaljulagoset-2019.pdf

Instituto Nacional de Estadística e Informática - INEI (2018). Encuesta Nacional Agropecuaria 2016. Recuperado de https://webinei.inei.gob.pe/anda_inei/index.php/ catalog/655

Instituto Peruano de Economía (2018). Indice de Competitividad Regional INCORE 2018. Recuperado de https://www.ipe.org.pe/portal/ incore-2018-indice-de-competitividad-regional/

Karami, E. \& Rezaei-Moghaddam, K. (2005). Modeling determinnants of agricultural production cooperatives performance in Iran. Agricultural Economics, 33, 305-314. https://doi.org/10.1111/j.1574-0864.2005.00069.x

López, L. \& Calderón, G. (2006). Análisis de las dinámicas culturales al interior de un clúster empresarial. Revista Estudios Gerenciales, 99, 13-37.

Lozano, M. (2010). Modelos de asociatividad: estrategias efectivas para el desarrollo de las pymes. Revista Escuela de Administración de Negocios, (68), 175-178. Recuperado de https://journal.universidadean.edu.co/index.php/Revista/article/view/505

Mamani Oño, I. (2017). Experiencias exitosas de asociatividad de los agricultores familiares en los sistemas agroalimentarios. El caso de la red andina de productores de quinua. Santiago de Chile: FAO.

Mejía López, R. (2013). Editorial. Revista Nacional de Agricultura, 958, 5.

Melo Torres, L. I., Melo Torres, M.M. \& Fonseca Pinto, D. E. (2017). The Associativity: a local development strategy for Ocamonte (APCO) coffee growers in Santander, Colombia. Acta Agronómica, 66(4), 538-543. https://doi.org/10.15446/acag. v66n4.61389

Ministerio de Agricultura y Riego (2012). IV Censo Nacional Agropecuario 2012. Recuperado de https://www.agrorural.gob.pe/dmdocuments/resultados.pdf

Ministerio de Agricultura y Riego - Minagri (2015). Estrategia Nacional de Agricultura Familiar 2015 -2021. Lima: Minagri.

Ministerio de la Producción del Perú (s.f). Cuaderno de Trabajo - Asociatividad Empresarial. Perú: Dirección General de Innovación, Transferencia Tecnológica y Servicios Empresariales del Ministerio de la Producción.

Miranda, A.B. (2003). Capital social, institucionalidad y territorios el caso de Centroamérica. 2a edición. Nicaragua y Costa Rica: IICA.

Olson, M. (1992). La lógica de la acción colectiva: bienes públicos y la teoría de grupos. México, D. F.: Limusa.

Paredes, H. \& Fort, R. (2018). En los márgenes del boom agroexportador: articulación de los pequeños productores a las cadenas de valor globales. En Perú: el problema agrario en debate. SEPIA XVII / Seminario Permanente de Investigación Agraria. Lima: Sepia.

Ruiz Fonseca, A. (2001). Asociatividad en las Pymes. Recuperado de https://www.gestiopolis.com/asociatividad-pymes/ 
Salas, V. (2017). La asociatividad como motor de la agricultura. Economía y Sociedad, 91, 45-51.

Sociedad de Agricultores de Colombia (2013). El papel del Estado para la promoción de la asociatividad. Revista Nacional de Agricultura, 958, 11-13.

Stoian, D. \& Donovan, J. (2010). Articulación del mundo campesino con el mercado - Integración de enfoques de medios de vida y cadena productiva. VI Semana Científica del Catie. Turrialba (Costa Rica), 14-16.

Suárez Pineda, M. \& Suárez Pineda, L. (2017). El conocimiento, determinante en procesos de asociatividad: una experiencia en conformación de redes empresariales. Revista Encuentros, 15(2), 83-97. https://doi.org/10.15665/re.v15i2.850

Tanaka, M. (2001). Participación popular en politicas sociales: cuándo puede ser democrática y eficiente y cuándo todo lo contrario. Lima: IEP.

Temple, D. (2008). Estructura comunitaria y reciprocidad: del quid-pro-quo histórico al economicidio. Serie Ensayos para repensar el pais. Universidad de Indiana.

Toledo Velásquez, D. I. (2016). Asociatividad agraria y estrategias productivas: explorando sus múltiples facetas desde la perspectiva de productores y productoras de la Asociación Talpuy de Sapallanga, región Junin (trabajo no publicado). Lima: Pontificia Universidad Católica del Perú.

Urrutia, J., Remy, M. I. \& Burneo, M. L.(2019). Comunidades campesinas y nativas en el contexto neoliberal peruano: una lectura del CENAGRO y las hojas de información complementarias. Lima: IEP, CEPES.

Vega Centeno, P. (1992). Autoconstrucción y reciprocidad: cultura y solución de problemas urbanos. Lima. Cenca, FOMCIENCIAS.

Vegas Rodríguez, J. C. (2008). Asociatividad [presentación de PowerPoint]. Lima: Ministerio de Comercio Exterior y Turismo del Perú.

Velarde Herz, F. (2017). El espacio público en la ciudad popular: la vida entre laderas. Bulletin de l'Institut français d'études andines [en línea], 46(3). https://doi.org/10.4000/ bifea. 885 